Received September 16, 2019

Revised November 14, 2019

Accepted November 25, 2019

\section{Pneumocephalus following fluoroscopy-guided lumbar epidural injection in elderly patients: two cases report and a review of Korean literatures - Two cases report -}

\section{Sun Kyung Park, Sang Hyun Park, Bang Won Lee, Woo Jin Cho, and Yun Suk Choi}

Department of Anesthesiology and Pain Medicine, Jeju National University Hospital, Jeju, Korea

Background: Pneumocephalus can originate from accidental dural puncture while performing epidural block using the loss-of-resistance (LOR) technique with an air-filled syringe.

Case: We present two cases of pneumocephalus after lumbar epidural block under fluoroscopy for pain control in elderly patients.

Conclusions: Lumbar epidural block should be performed under fluoroscopic guidance in elderly patients with severe lesions. The physician should be aware of the increased possibility of a dural puncture occurring due to anatomical changes in older patients. The use of saline is recommended for the LOR technique. A contrast injection should be used together with the LOR technique to locate the epidural space. If a dural puncture occur, the patient should be carefully monitored to determine whether pneumocephalus has developed.

Keywords: Back pain; Complications; Fluoroscopy; Headache; Pneumocephalus.

\author{
Corresponding author \\ Yun Suk Choi, M.D. \\ Pain Medicine, Jeju National University \\ School of Medicine, 15 Aran 13-gil, \\ Jeju 63241, Korea \\ Tel: 82-64-717-2025 \\ Fax: 82-64-717-2042 \\ E-mail: solafide5@hanmail.net
}

Pneumocephalus is an extremely rare complication of dural punctures. Early diagnosis, correct management, and patient counseling promote a successful management [1] Unlike previous blind epidural block procedures, the recent introduction of fluoroscopy has made performing epidural block safer. The need for epidural steroid injections is increasing with the growing elderly population. The development of safe interventions for pain control is especially important in elderly patients because of the high risk of complications due to multiple underlying diseases as well as generalized frailty. Herein, we report two cases of pneumocephalus following unintentional dural puncture in two elderly patients during a fluoroscopy-aided interlaminar lumbar steroid injection.

\section{CASE REPORT}

We obtained written informed consent from the patients' guardians.

\section{Case 1}

An 82-years-old woman (height $157 \mathrm{~cm}$, weight $56 \mathrm{~kg}$ ) presented with bilateral buttock pain. Three years prior, she received multiple injections for epidural block. Magnetic resonance imaging (MRI) of the lumbar spine revealed spondylolytic spondylolisthesis, a bulging disc, ligamentum flavum (LF) thickening, and moderate central stenosis at L4/5 (Fig. 1). On presentation, a fluoroscopy-guided epidural steroid injection was scheduled. In the prone

This is an Open Access article distributed under the terms of the Creative Commons Attribution Non-Commercial License (http://creativecommons.org/licenses/by-nc/4.0) which permits unrestricted non-commercial use, distribution, and reproduction in any medium, provided the original work is properly cited.

Copyright (c) the Korean Society of Anesthesiologists, 2020 


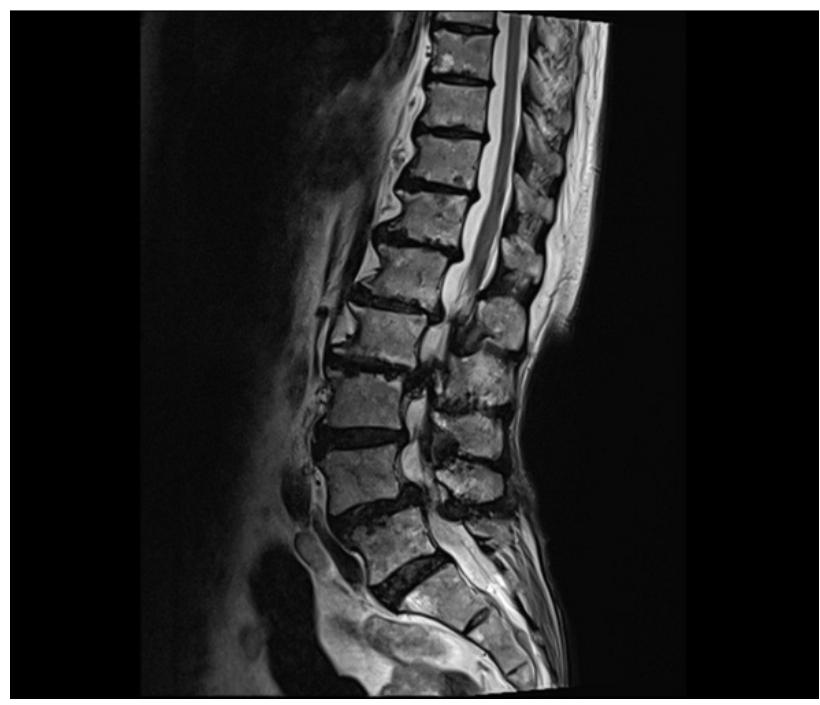

Fig. 1. Lumbar MRI of patient (case 1) shows spondylolytic spondylolisthesis, bulging disc, ligamentum flavum thickening, and moderate central stenosis in L4/5. MRI: magnetic resonance imaging.

position, the injection site was disinfected and $1 \%$ lidocaine was injected. The L4/5 interspace was identified under fluoroscopy, and an 18-gauge Tuohy needle was advanced into the interlaminar space under an anterior-posterior (AP) fluoroscopic view. The needle was advanced into the epidural space under lateral fluoroscopy using the loss of resistance (LOR) technique with a $1.0 \mathrm{ml}$ air-filled syringe. After checking for the negative aspiration of cerebrospinal fluid (CSF), $0.5 \mathrm{ml}$ of contrast agent (Pamiray 250 Injection ${ }^{\circledR}$, Dong Kook Pharm. Co., Korea) was injected. After examining the AP and lateral fluoroscopic images, a mixture of $0.125 \%$ ropivacaine $(6 \mathrm{ml})$ and $10 \mathrm{mg}$ triamcinolone was injected (Fig. 2). In the recovery room, the patient's blood pressure was 140/60 $\mathrm{mmHg}$, and her heart rate (HR) was 77 beats/min. Thirty minutes later, her blood pressure declined to $82 / 53 \mathrm{mmHg}$, and her HR increased to 88 beats/min. Supplement oxygen was administered using a facial mask with reservoir and intravenous fluids were started, and ephedrine ( $5 \mathrm{mg}$ ) was injected. The patient exhibited intense perspiration, and complained of a severe occipital headache (numerical rating scale [NRS] 7), dizziness and nausea. Her body temperature decreased to $35^{\circ} \mathrm{C}$. The hypothermia improved $1 \mathrm{~h}$ after oxygen therapy was initiated and warming intervention were applied. The patient was referred to a neurologist. Neurological examinations revealeds no deficits; however, pneumocephalus was suspected. Brain computed tomography (CT) scans revealed multiple locules of air in the cranial cavity and air at
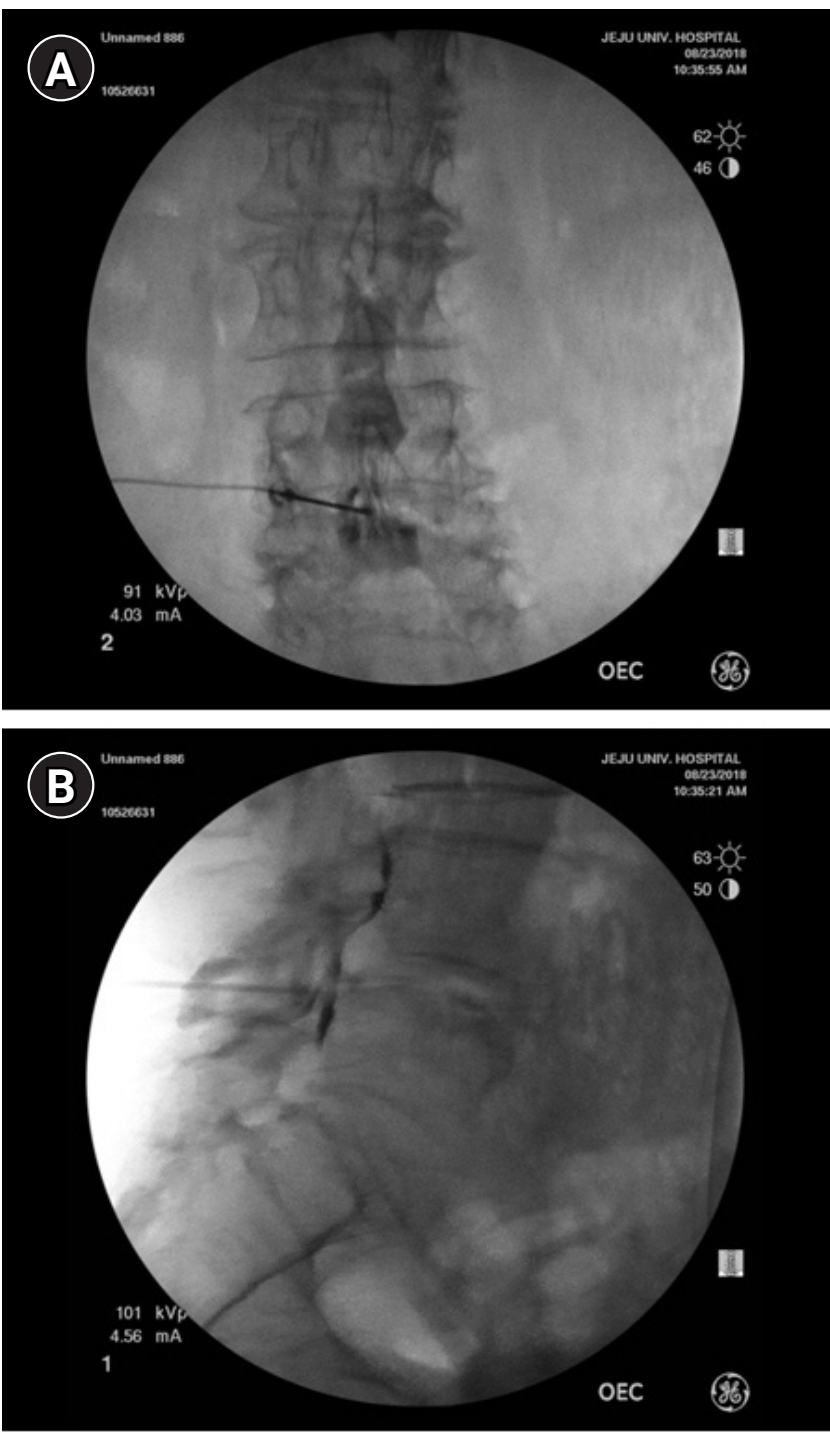

Fig. 2. Fluoroscopic image of patient (case 1). (A) AP post-contrast image. (B) Lateral post-contrast image. Two images show intrathecal injection. AP: anterior-posterior.

the velum interpositum, anterior and posterior interhemispheric fissure, supracerebellar cistern and right sylvian fissures (Fig. 3). The patient was admitted to the hospital and oxygen was administered ( $5 \mathrm{~L} / \mathrm{min}$ ) using a facial mask with a reservoir. Her headache was reduced by $50 \%$ after 24 $\mathrm{h}$ and she was discharged the next day. Five days after discharge, her headache had completely resolved. Subsequent physical examination at follow-up was negative for pneumocephalus.

\section{Case 2}

An 88-years-old woman (height $146 \mathrm{~cm}$, weight $50 \mathrm{~kg}$ ) presented with complaints of low back and bilateral buttock 


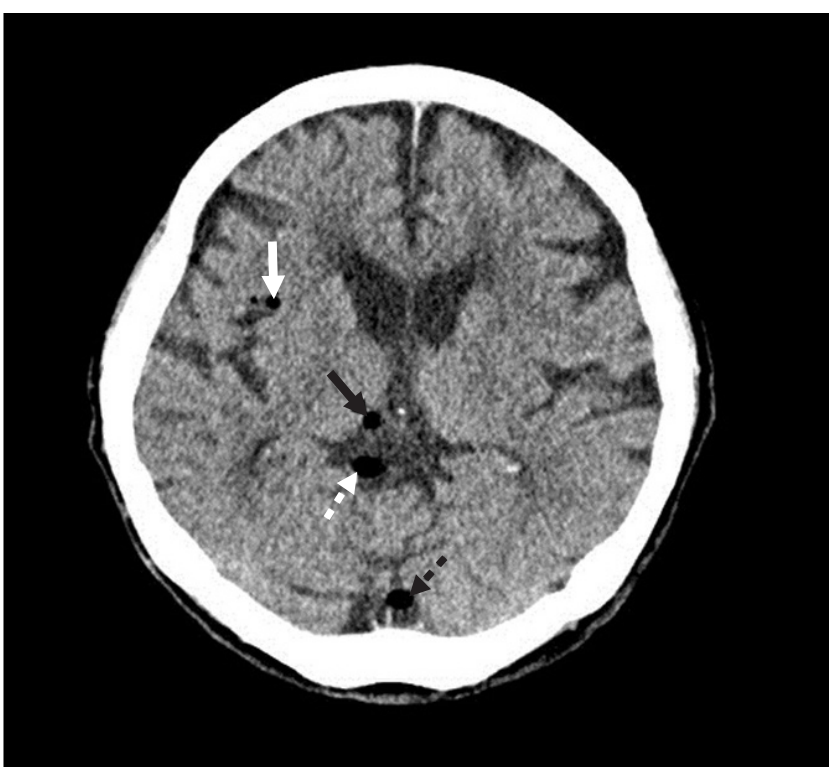

Fig. 3. Axial cranial CT scan (case 1) revealing multiple locules of air in the cranial cavity and air at velum interpositum (black arrow), posterior interhemispheric fissure (black dotted arrow) supracerebellar cistern (white dotted arrow) and right sylvian fissure (white arrow). CT: computed tomography.

pain as well as numbness in both lower extremities. The patient was suffering from a gait disorder which severely restricted her mobility without a wheelchair. A history of congestive heart failure and cerebral infarction was reported. The patient also had a 5-year history of lumbar nerve root and epidural blocks to manage her symptoms. MRI revealed multiple old compression fractures (T10-12, L2-4), vertebroplasty at T7, 10, 11, and L4 and spinal canal stenosis (severe central stenosis $\mathrm{Ll} / 2$, bilateral mild foraminal stenosis T10-L1) (Fig. 4). On presentation, a fluoroscopy-guided epidural steroid injection was scheduled. In the prone position, the injection site was disinfected and $1 \%$ lidocaine was injected. The L5/S1 interspace was identified by fluoroscopy, and an 18-gauge Tuohy needle was advanced into the interlaminar space under an AP fluoroscopic view. The needle was advanced into the epidural space using the LOR technique with a 1-ml air-filled syringe though the LF and a location where the syringe would not rebound. However, CSF aspirated, and on injecting $0.5 \mathrm{ml}$ of the contrast, a dural puncture was confirmed through the fluoroscopic AP and lateral images (Fig. 5). The procedure was aborted immediately. After explaining the occurrence of the dural puncture to the patient, she was sent to the recovery room. Her blood pressure was 103/61 mmHg, HR was 87 beats/min and oxygen saturation was $96 \%$. Normal saline was infused intravenously and oxygen $(5 \mathrm{~L} / \mathrm{min})$ was administered using a facial

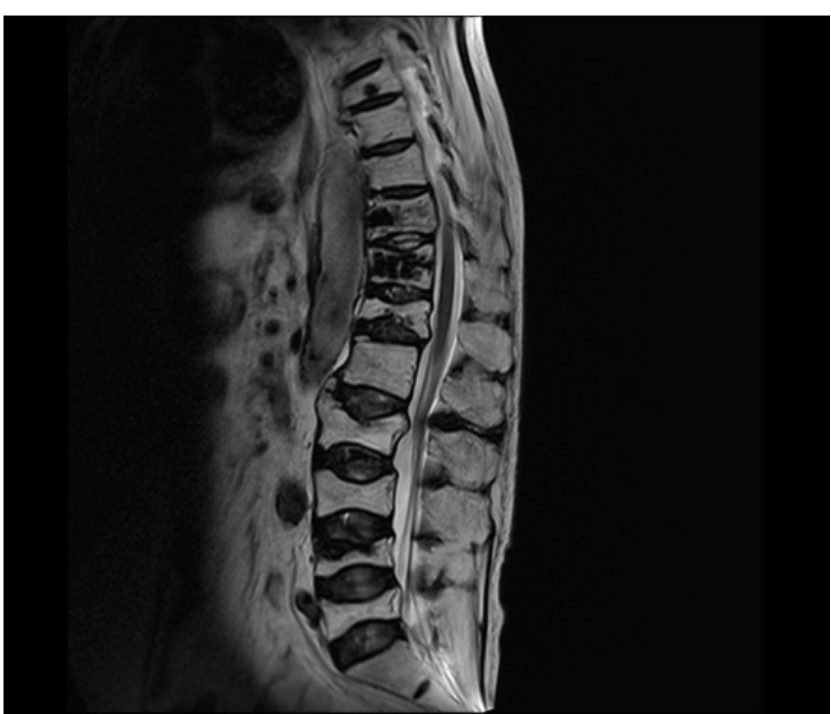

Fig. 4. Lumbar MRI of patient (case 2) shows multiple old compression fractures (T10-12, L2-4), vertebroplasty at T7, 10, 11 , and L4 and spinal canal stenosis (severe central stenosis L1/2, bilateral mild foraminal stenosis T10-L1). MRI: magnetic resonance imaging.
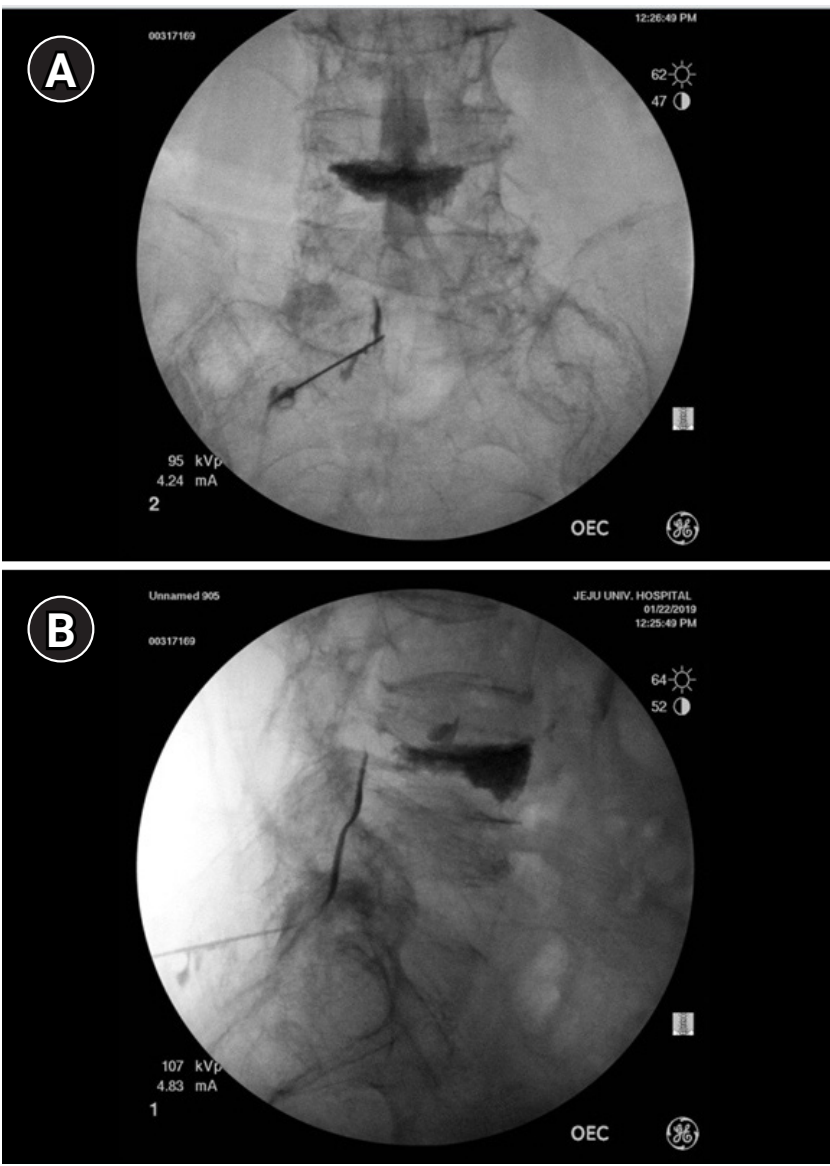

Fig. 5. Fluoroscopic image of patient (case 2). (A) AP post-contrast image suggesting intrathecal injection. (B) Lateral post-contrast image suggesting intrathecal injection. AP: anterior-posterior. 
mask with a reservoir. One hour later, she complained of severe (NRS score 5-6) bilateral temporal headache and pain on the top of her head that persisted regardless of posture changes. Tramadol administration did not reduce her headache. A case of pneumocephalus was suspected. Brain CT examination showed the presence of air at the ventricular frontal horn, anterior interhemispheric fissure, right ambient cistern, and around bilateral cavernous sinuses (Fig. 6). The patient was admitted to the hospital after an explanation was provided to her and her guardian. After the admission, oxygen ( $5 \mathrm{~L} / \mathrm{min}$ ) was administered. Twenty-two hours later, the headache was reduced by $70 \%$. Follow-up brain CT confirmed the reduction of the pneumocephalus. Therefore, she was discharged the next day. Follow-up 2 weeks after
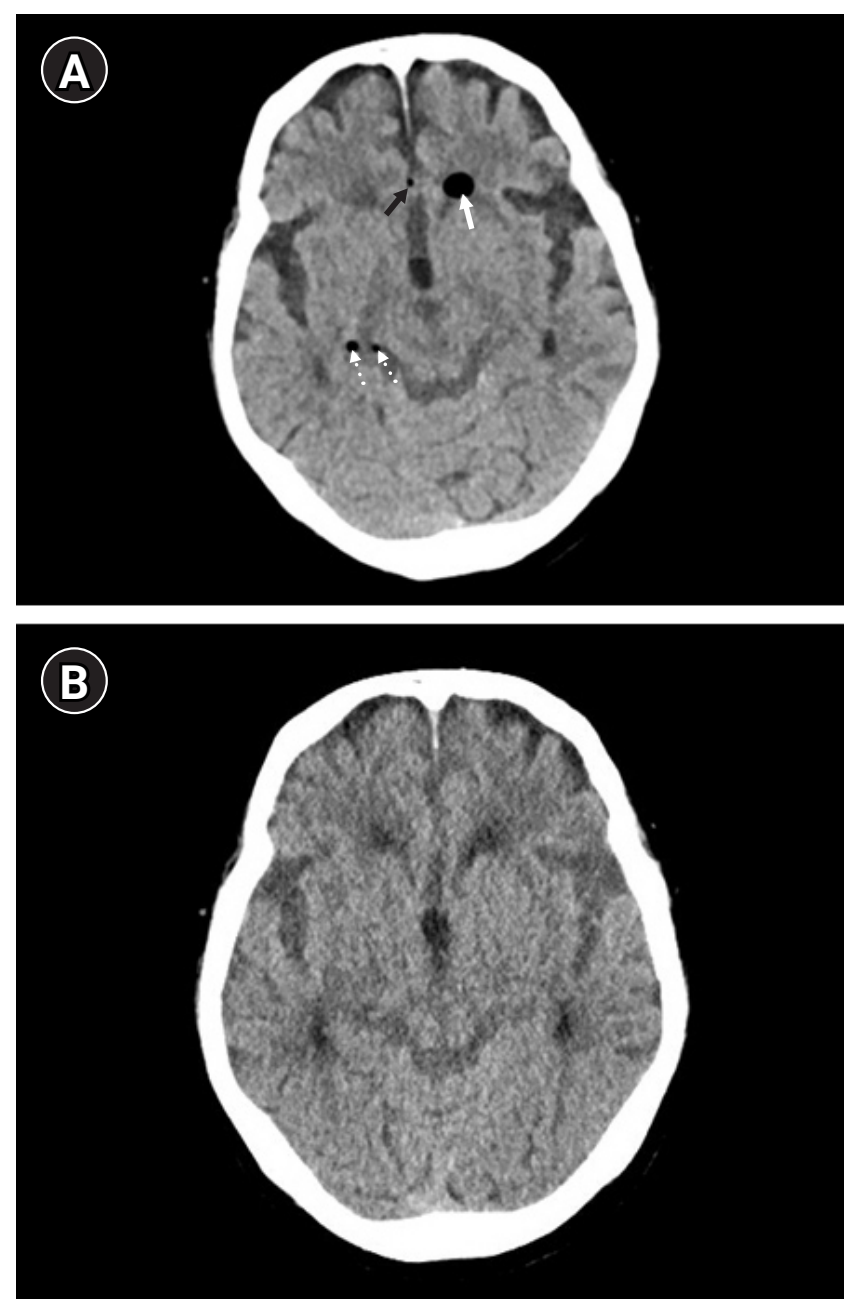

Fig. 6. (A) Axial cranial CT scan (case 2) demonstrating air in the lateral ventricular frontal horn (white arrow), anterior interhemispheric fissure (black arrow), and right ambient cistern (white dotted arrow), and around the bilateral cavernous sinuses of the patient (case 2). (B) Follow up CT scan showed decreased pneumocephalus (next day). CT: computed tomography. discharge, indicated complete resolution with no complaint of headache. Her physical examination was negative for pneumocephalus.

\section{DISCUSSION}

In both cases, the elderly patients described each received, a fluoroscopy-guided lumbar epidural block. However, pneumocephalus occurred following a dural puncture in each case and was resolved only after oxygen therapy. Pneumocephalus is the presence of air in the intracranial compartments such as the intraventricular, intraparenchymal, subarachnoid, subdural and epidural space of the brain. Headache due to the presence of intrathecal air, following pneumoencephalography is well reported. This procedure was widely performed between 1919 and 1970 . In pneumoencephalography, CSF is aspirated by dural puncture of the lumbar spine and $35-50 \mathrm{ml}$ of air is injected to visualize the ventricles and cortical status. A wide range of side effects have been reported in association with pneumoencephalography, including headache, vomiting, pyrexia, tachycardia, changes in blood pressure neck stiffness, mental confusion, and temperature disorders. Resolution of pneumocephalus after injection of a large volume of air (20-50 $\mathrm{ml})$ requires $1-2$ weeks.

Conservative treatments for pneumocephalus include hydration, bed rest, use of analgesics and $100 \%$ oxygen therapy. Concentrated oxygen therapy decreases the partial pressure of nitrogen in the blood with an increase in the concentration gradient. This hastens the diffusion of intracranial air into the blood stream. The two patients described improvement with oxygen therapy.

To assess LOR, air or fluid is routinely used. Saline, a local anesthetic, and contrast are usually used in the LOR technique for epidural block. Use of air LOR (ALOR) was prevalent until the 1980s; however, because there are reported side effects associated with ALOR such as dural puncture with or without postdural puncture headache (PDPH), pneumocephalus, spinal cord and nerve root compression subcutaneous emphysema and paresthesia, practitioners prefer saline over the alternatives [2]. However, a systematic review or randomized controlled trial have reported no difference in safety between the use of air and saline during epidural block for gynecological cases [3]. The use of saline with LOR for epidural block in patients with chronic pain exhibited a lower incidence of pneumocephalus than ALOR; no large-scale studies have been 
conducted recently [4].

Verdun et al. [1] recommended the use of saline to prevent pneumocephalus. For a clinician more familiar with air injection, the study recommended using a mixture of 1-2 ml saline and 1-2 $\mathrm{ml}$ air. The use of saline and contrast to increase positivity has been suggested. For severe cases of central canal stenosis in the lumbar epidural block area, interlaminar (or at other levels) or bilateral transforaminal injections may be recommended. In the first case, the dural puncture occurred due to the advancement of the needle into a region with severe central canal stenosis. Because no CSF was aspirated, the practitioner did not carefully scrutinize the fluoroscopy images and continued with the procedure. In the second case, the procedure was aborted due to the confirmation of pneumocephalus. It is important to carefully observe an intrathecal injection during fluoroscopy-guided epidural block. The contrast pattern of intrathecal injection rapidly descends in the CSF with gravity and outlines the excited nerve roots on the lateral view.

There are two types of headache seen after penetration of the dura mater; CSF leakage and pneumoencephalopathy due to intrathecal air. Headaches caused by pneumocephalus, reportedly, occur s few hours after the treatment and usually continue for a few days. The patient usually recovers naturally. The headache may even occur when the patient is supine. In case of PDPH, the headache may occur 24-48 h after dural puncture, and an epidural blood patch is sometimes required. PDPH worsens depending on the sitting position [1].

Fluoroscopy-guided epidural block was attempted and failed in both patients. In normal adults, in the lumbar area, the epidural space is the largest, the LF is the thickest, and the midline gap is the smallest, enabling an easier epidural block. Zaki [5] reported the structural difference of the LF in the cadavers of older adults. Reduction of the elastic to collagen area ratio affected the spinal ligament and particularly lumbar LF ossification. Other obstacles including, increased vasculature, absence of the midline gaps, and fragmentation and rupture of the elastic fibers are reported to have occurred. Hogan [6] reported that, due to lumbar degenerative changes, loss of intervertebral disc height occurs causing buckling of the LF. This reduces the space between the posterior elements, causing the spinous process to stick together. This in turn causes needle insertion to be difficult during an epidural block. The patients in this study were above 80 years in age. The treatment was initiated at the lower level of the severe degenerative lesion of the lumbar spine. Nonetheless, due to the severe degenerative changes, pneumocephalus developed.

In elderly patients, even with the aid of fluoroscopy, dural punctures are inevitable during epidural block owing to anatomical changes in the spine. Thus, a blind epidural block for should be avoided in elderly patients. According to Table 1 [7-12], which contains reported cases of pneumocephalus, some Korean practitioners have performed blind epidural blocks. Although the practitioner may be very familiar with the technique, in blind epidural block, $30-40 \%$ of blocks are performed incorrectly [13]. We would like to emphasize that, careful identification of the location of the epidural space is strongly recommended to ensure safety. This is particularly true in elderly patients, during an epidural block using the LOR technique guided by fluoroscopy and contrast injection [14]. In addition, even when CSF is not aspirated when performing epidural blocks,

Table 1. Pneumocephalus Cases Resulting from Epidural Block for Pain Control in the Korean Literatures

\begin{tabular}{|c|c|c|c|c|c|c|c|c|}
\hline Authors & $\begin{array}{c}\text { Year of } \\
\text { publication }\end{array}$ & $\begin{array}{l}\text { Age of } \\
\text { patient }\end{array}$ & $\begin{array}{l}\text { Epidural LOR } \\
\text { technique } \\
\text { (air or saline/ } \\
\text { volume) }\end{array}$ & $\begin{array}{c}\text { Procedure level } \\
\text { (cervical/thoracic/ } \\
\text { lumbar) }\end{array}$ & $\begin{array}{l}\text { Fluoroscopy } \\
\text { or blind }\end{array}$ & $\begin{array}{l}\text { Symptom/ } \\
\text { onset time }\end{array}$ & $\begin{array}{l}\text { Pneumocepha- } \\
\text { lus resolution } \\
\text { in CT }\end{array}$ & $\begin{array}{l}\text { Duration of } \\
\text { symptom } \\
\text { resolution }\end{array}$ \\
\hline Han et al. [7] & 1996 & 38 & Air/9 ml & $\begin{array}{l}\text { Lumbar 3/4 interlami- } \\
\text { nar }\end{array}$ & Blind & Headache/1 h & Unknown & 4 days \\
\hline Ahn et al. [8] & 2012 & 70 & $\begin{array}{l}\text { Unknown/ } \\
\text { unknown }\end{array}$ & $\begin{array}{l}\text { Lumbar 3/4 interlami- } \\
\text { nar }\end{array}$ & Unknown & $\begin{array}{l}\text { Headache, nausea/ } \\
\text { immediately after } \\
\text { the procedure }\end{array}$ & 5 days & 3 days \\
\hline Kim et al. [9] & 2012 & 68 & Air/8 ml & $\begin{array}{l}\text { Lumbar 4/5 interlami- } \\
\text { nar }\end{array}$ & Blind & Syncope/30 min & Unknown & 1 day \\
\hline Jung and Park [10] & 2001 & 58 & Air/3-4 ml & $\begin{array}{l}\text { Lumbar 3/4 interlami- } \\
\text { nar }\end{array}$ & Blind & $\begin{array}{l}\text { Headache, nausea/ } \\
5 \text { min }\end{array}$ & 3 days & 5 days \\
\hline Kim et al. [11] & 2015 & 54 & Air/1 ml & $\mathrm{C} 7 / \mathrm{T} 1$ interlaminar & Fluoroscopy & Headache/4 h & 16 days & 21 days \\
\hline Chung et al. [12] & 2017 & 58 & Air/unknown & $\begin{array}{l}\text { Lumbar 4/5 interlami- } \\
\text { nar }\end{array}$ & Blind & $\begin{array}{l}\text { Headache and } \\
\text { seizure } / 5 \text { min }\end{array}$ & Unknown & 11 days \\
\hline
\end{tabular}

LOR: loss-of-resistance, CT: computed tomography. 
contrast injection should be used to confirm the subdural or subarachnoid injection, intravascular injection, and facet injection [15].

In conclusion, lumbar epidural block should be performed under fluoroscopic guidance in elderly patients with severe lumbar degenerative changes. The physician should be aware of the increased possibility of dural punctures due to anatomical changes. The use of saline is recommended for the LOR technique, and contrast injections should be used together with the LOR technique locate epidural space. If a dural puncture does occur, the patient should be carefully monitored to determine whether pneumocephalus has developed.

\section{ACKNOWLEDGEMENTS}

This work was supported by the 2020 education, research and student guidance grant funded by Jeju National University.

\section{CONFLICTS OF INTEREST}

No potential conflict of interest relevant to this article was reported.

\section{AUTHOR CONTRIBUTIONS}

Conceptualization: Yun Suk Choi. Data acquisition: Sun Kyung Park, Bang Won Lee. Supervision: Yun Suk Choi. Writing-original draft: Sun Kyung Park. Writing-review\&editing: Sang Hyun Park, Woo Jin Cho.

\section{ORCID}

Sun Kyung Park, https://orcid.org/0000-0002-4133-5806

Sang Hyun Park, https://orcid.org/0000-0003-4968-6755

Bang Won Lee, https://orcid.org/0000-0003-3786-5668

Woo Jin Cho, https://orcid.org/0000-0002-4338-5428

Yun Suk Choi, https://orcid.org/0000-0002-7983-8089

\section{REFERENCES}

1. Verdun AV, Cohen SP, Williams BS, Hurley RW. Pneumocephalus after lumbar epidural steroid injection: a case report and review of the literature. A A Case Rep 2014; 3: 9-13.
2. Brogly N, Guasch E, Alsina E, García C, Puertas L, Dominguez A, et al. Epidural space identification with loss of resistance technique for epidural analgesia during labor: a randomized controlled study using air or saline-new arguments for an old controversy. Anesth Analg 2018; 126: 532-6.

3. Schier R, Guerra D, Aguilar J, Pratt GF, Hernandez M, Boddu K, et al. Epidural space identification: a meta-analysis of complications after air versus liquid as the medium for loss of resistance. Anesth Analg 2009; 109: 2012-21.

4. Aida S, Taga K, Yamakura T, Endoh H, Shimoji K. Headache after attempted epidural block: the role of intrathecal air. Anesthesiology 1998; 88: 76-81.

5. Zaki SM. Study of the human ligamentum flavum in old age: a histological and morphometric study. Folia Morphol (Warsz) 2014; 73: 492-9.

6. Hogan QH. Epidural anatomy examined by cryomicrotome section. Influence of age, vertebral level, and disease. Reg Anesth 1996; 21: 395-406.

7. Han CS, Yu JS, Kim IH, Kim YJ, Kim CS, Ahn KR. Headache and pneumocephalus after lumbar epidural block -a case report-. Korean J Pain 1996; 9: 251-5.

8. Ahn B, Noh SM, Kim NH. Pneumocephalus after an epidural injection. J Korean Neurol Assoc 2012; 30: 148-50.

9. Kim YD, Lee JH, Cheong YK. Pneumocephalus in a patient with no cerebrospinal fluid leakage after lumbar epidural block - a case report -. Korean J Pain 2012; 25: 262-6.

10. Jung SK, Park KH. Pneumocephalus after epidural steroid injection -a case report-. Korean J Pain 2001; 14: 276-9.

11. Kim YD, Ham HD, Moon HS, Kim SH. Delayed pneumocephalus following fluoroscopy guided cervical interlaminar epidural steroid injection: a rare complication and anatomical considerations. J Korean Neurosurg Soc 2015; 57: 376-8.

12. Chung YW, Seo HY, Lee DH, Kim SK. Pneumocephalus after interlaminar lumbar epidural block. J Korean Orthop Assoc 2017; 52: 552-5.

13. Landa J, Kim Y. Outcomes of interlaminar and transforminal spinal injections. Bull NYU Hosp Jt Dis 2012; 70: 6-10.

14. Stojanovic MP, Vu TN, Caneris O, Slezak J, Cohen SP, Sang CN. The role of fluoroscopy in cervical epidural steroid injections: an analysis of contrast dispersal patterns. Spine (Phila Pa 1976) 2002; 27: 509-14.

15. Goodman BS, Posecion LW, Mallempati S, Bayazitoglu M. Complications and pitfalls of lumbar interlaminar and transforaminal epidural injections. Curr Rev Musculoskelet Med 2008; 1:212-22. 